\title{
SISTEM INFORMASI KEARSIPAN ONLINE PADA PT. TOWER BERSAMA GROUP ( TBG ) BANJARMASIN
}

\author{
Ibrahim $^{1)}$, Auliya Rahman ${ }^{2)}$ \\ ${ }^{1}$ Fakultas Teknologi Informasi, Universitas Islam Kalimantan Muhammad Arsyad Al Banjari Banjarmasin \\ Email : Terrasin06@gmail.com \\ ${ }^{2}$ Fakultas Teknologi Informasi, Universitas Islam Kalimantan Muhammad Arsyad Al Banjari Banjarmasin \\ Email : auliyarahmankom@gmail.com
}

\begin{abstract}
Abstrack
Sistem Informasi merupakan suatu komponen yang sangat penting dalam kehidupan masyarakat saat ini. Dengan memanfaatkan internet, informasi tidak lagi menjadi suatu hal yang sulit untuk disampaikan. Perkembangan internet sangat berguna bagi organisasi, sekolah, perguruan tinggi, perusahaan swasta, dan instansi pemerintahan di Indonesia sebagai media yang tepat untuk mengimplementasikan sistem informasi. Dengan perkembangan teknologi saat ini PT. Tower Bersama Group memerlukan Sistem Informasi kearsipan online ini merupakan suatu aplikasi yang berguna membantu proses penyimpanan dan pencarian data kegiatan yang dilakukan oleh setiap karyawan. Pencatatan online ini bisa meningkatkan secara efektif pencatatan dan sistem informasi kegiatan guna kecepatan dalam memperoleh informasin yang diinginkan. Aplikasi ini dibuat dengan mengaplikasikan Visual Basic 6.0 untuk menghasilkan sistem informasi data kegiatan. Untuk pembuatan sistem informasi ini menggunakan bahasa pemograman PHP dan database MySQL.
\end{abstract}

Kata Kunci: Pencatatan Online, Visual Basic,sistem informasi,arsip

\section{PENDAHULUAN}

Sistem informasi kearsipan adalah sebagai catatan history atau rekaman setiap kegiatan yang dilakukan dalam ruang lingkup pekerjaan, sehingga bisa dipertanggungjawabkan bila suatu saat diperlukan untuk melihat apa saja kegiatan yang pernah terjadi sebelumnya.

Kesulitan yang didapat bila tidak menggunakan sistem kearsipan adalah ketika melakukan pencarian informasi yang lama, perlu ketelitian dalam membuka setiap lembar halaman untuk mendapatkan informasi yang diinginkan. Selain itu juga kesulitan dalam berbagi/sharing dengan rekan-rekan lain yang ingin mengetahui informasi kegiatan atau kejadian apa saja selama 1 minggu, 1 bulan, atau 1 tahun sebelumnya. Kemudian hal lain yang turut menjadi perhatian kami adalah adanya kekhawatiran hilangnya informasi akibat sistem arsip manual terkena cairan ataupun ada lembaran halaman yang hilang. Hal inilah yang membuat kami mengangkat permasalahan ini untuk dicarikan solusi masalahnya.

Di dalam organisasi PT. Tower Bersama Group, terdapat berbagai macam divisi, dan salah satunya adalah divisi O\&M. divisi ini merupakan salah satu bagian dari divisi yang bertanggung jawab melaksanakan operation and maintenance (O\&M) pemeliharaan tower perusahaan telekomunikasi pada daerah Banjarmasin.

\section{METODE PENELITIAN}

- Objek Penelitian

Objek penelitian ini dilakukan di PT.Tower Besama Group jalan Mawar Banjarmasin Provinsi Kalimantan Selatan

- Metode Pengumpulan Data.

Untuk memperoleh data yang diperlukan dalam penyusunan penelitian ini dengan menggunakan metode pengumpulan data sebagai berikut:

1. Wawancara atau interview

Wawancara adalah suatu metode yang digunakan untuk memperoleh data dengan cara mengajukan pertanyaan-pertanyaan secara langsung. Dalam hal ini penulis melakukan wawancara dengan pihak staf pegawai PT. Tower Bersama Group pada bagian operation and maintenance dan 
Manager tentang bagaimana sistem pencatatan tersebut.

Pengamatan Langsung atau

Observasi.

Observasi adalah metode pengumpulan data dengan cara mengamati secara langsung proses pencatatan kegiatan di kantor tersebut.

\section{Studi Pustaka}

Studi pustaka adalah suatu metode pengumpulan data dengan menggunakan buku-buku dan pencarian di internet sebagai bahan referensi dalam penulisan laporan dan pembuatan sistem.

- Tahapan Tahapan Pembuatan Sistem

Dalam pengembangan sistem ini, ada beberapa tahapan yang harus dilakukan. Adapun tahapan tersebut adalah sebagai berikut:

1. Analisa Sistem

Dalam membangun sistem informasi ini diperlukan perencanaan yang baik agar dihasilkan sistem yang dapat berjalan optimal. Tahap perencanaan ini terbagi atas 2 yaitu:

a. Menentukan tujuan pembuatan sistem kearsipan Tujuan pembuatannya adalah sebagai media untuk input data laporan operation and maintenance yang terjadi di PT. Tower Bersama Group.

b. Menentukan siapa yang akan menjadi pemakai

Perancangan sistem informasi ini diperuntukkan untuk bagian para staf karyawan, dan manager di suatu area PT. Tower Bersama Group.

2. Perancangan Sistem

Proses perancangan yang baik diperlukan untuk pembuatan program tak terkecuali dalam pembuatan sistem informasi yang baik. Perancangan sistem secara terperinci, dilakukan dengan cara:
a. Rancangan Menu
b. Rancangan Database
c. Relasi Antar Tabel
d. Diagram Konteks
e. Data Flow Diagram (DFD)
f. Rancangan Tampilan
g. Rancangan Output dan
Laporan
h. Pembuatan Program
Pembuatan Sistem logbook ini dibuat menggunakan bahasa pemrograman PHP dan MySQL sebagai pengelola databasenya.

3. Testing Aplikasi

Pada tahap ini, dilakukan uji terhadap sistem yang telah selesai dibuat dengan menggunakan jaringan dengan dua buah komputer dengan salah satu komputer digunakan sebagai server dan yang lain sebagi client. Proses uji coba ini diperlukan untuk memastikan bahwa sistem yang dibuat tersebut sudah benar, sesuai dengan yang diharapkan, dan tidak ada kesalahan-kesalahan yang terkandung di dalamnya.

\section{HASIL DAN PEMBAHASAN}

\section{Tampilan Awal Halaman Login}

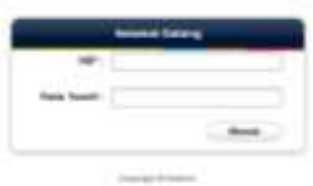

Gambar Halaman Login

Halaman pengguna login, Disini pengguna memasukkan NIP dan kata sandi untuk bisa mengakses logbook.

\section{Tampilan Halaman Catatan Kegiatan Pengguna}

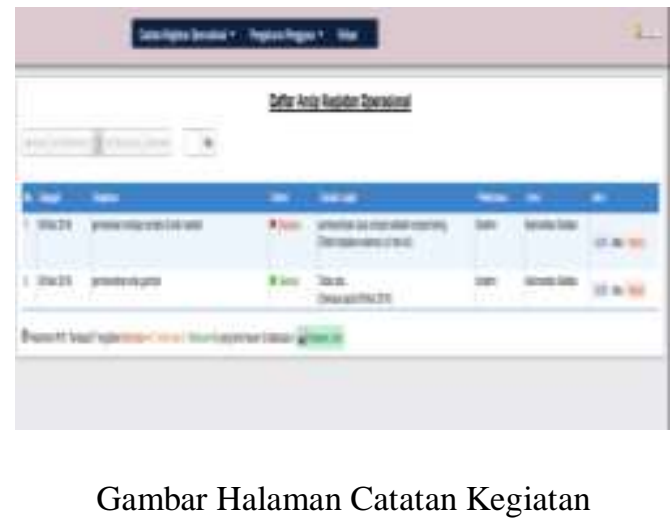


Halaman semua catatan kegiatan yang dilakukan oleh semua pengguna. Untuk level administrator, mempunyai hak untuk melakukan perubahan data atau hapus kegiatan pengguna, sedangkan untuk level user, hanya bisa melakukan perubahan atau hapus data kegiatan yang diinput oleh pengguna itu sendiri. Tampilan Halaman Tambah Catatan Kegiatan Operasional

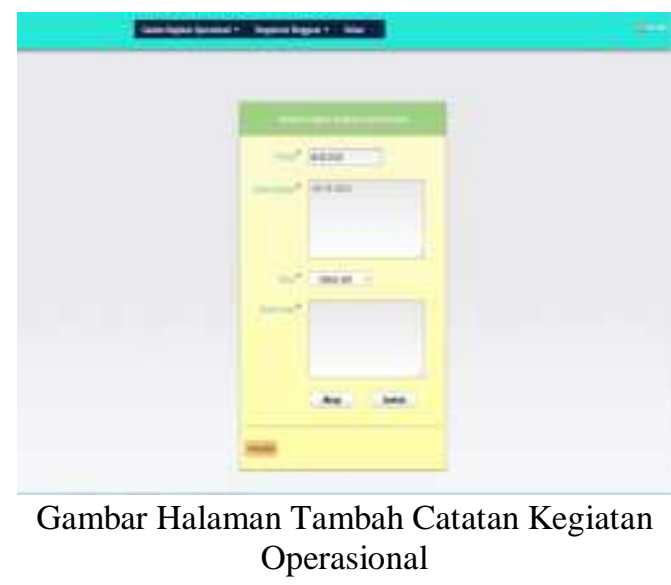

Pengguna melakukan input kegiatan yang pengguna lakukan untuk menyimpan kegiatan yang sudah dilakukan.

Tampilan Halaman Perbaharui Data Kegiatan

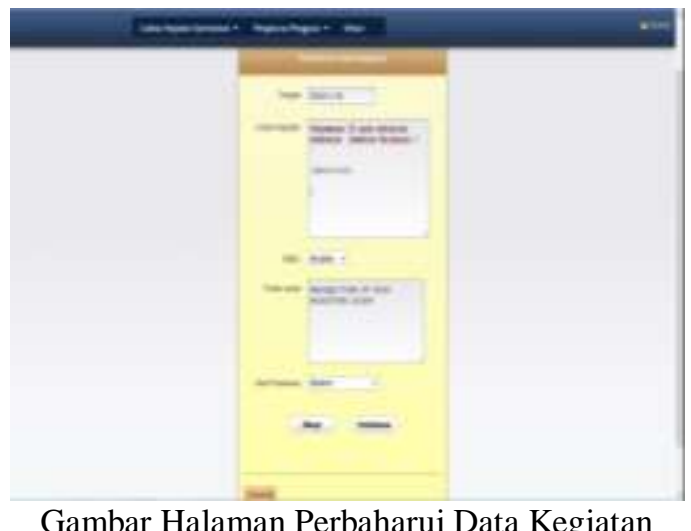

Halaman untuk melakukan perubahan data kegiatan atau update kegiatan yang dilakukan.

\section{KESIMPULAN}

Setiap kegiatan operation \& maintenance yang dilakukan harus dicatat sebagai catatan dan arsip kegiatan operasional di lingkungan PT Tower Bersama Group Banjarmasin agar dapat dipertanggungjawabkan. Sistem manual dalam penginputan kegiatan operasional yang selama ini dijalankan banyak memakan waktu, terlebih bila catatan kegiatan operasionalnya sangat banyak.

Dengan sistem komputerisasi, semuanya itu bisa teratasi. Kita dapat dengan dengan mudah melakukan penginputan dan pencarian data, tanpa memerlukan banyak waktu. Adapun manfaat lain program ini sebagai berikut:

1. Memudahkan dalam pencarian data kegiatan.

2. Menjaga keamanan data kegiatan.

3. Dapat mengurangi penggunaan kertas.

4. Ikut mensukseskan program pemerintah GO GREEN.

5. Menghemat pengeluaran pembelian kertas.

\section{REFERENSI}

Wahyono, Teguh, "Sistem Informasi Konsep Dasar, Analisis Desain \& Implementasi”, Graha Ilmu, Yogyakarta, 2004.

Hakim, Z. (2012, Agustus 16). Apa Itu Pemrograman Web? Retrieved April 2016, 28, from Pemrograman Web: http://www.zainalhakim.web.id/posting/apa-itupemrograman-web.html

Kasiman, P. (2009). Aplikasi Web dengan PHP dan MySQL. Yogyakarta: ANDI.

Peranginangin, K. (2006). Aplikasi WEB dengan PHP dan MySQL. Yogyakarta: ANDI.

Permana, B., \& dkk. (2011). Aplikasi Pengolahan Data Produksi Berbasis Web Di PT. Telehouse Engineering. Bandung: JBPTUNIKOMPP.

Wikipedia. (2016, April 8). HTML. Retrieved April 22, 2016, from Wikipedia: http://id.wikipedia.org/wiki/HTML

Wikipedia. (2016, Januari 3). PHP. Retrieved April 22, 2016, from Wikipedia: http://id.wikipedia.org/wiki/PHP 